\title{
Could a digital panoramic X-ray not detect a displaced fracture of the mandible?
}

\author{
Ahmad Albassal $^{1}$, Nuraldeen Maher Al-Khanati ${ }^{1,2} \wedge$, Munir Harfouch $^{1}$ \\ ${ }^{1}$ Department of Oral and Maxillofacial Surgery, Faculty of Dental Medicine, Damascus University, Damascus, Syria; ${ }^{2}$ Department of Oral and \\ Maxillofacial Surgery, Faculty of Dentistry, Syrian Private University, Damascus, Syria
}

Correspondence to: Dr. Nuraldeen Maher Al-Khanati. Department of Oral and Maxillofacial Surgery, Faculty of Dentistry, Syrian Private University, P.O. Box 36822, Damascus, Syria. Email: nuraldeen.alkhanati@gmail.com.

Submitted Sep 10, 2020. Accepted for publication Dec 14, 2020.

doi: $10.21037 /$ qims-20-1053

View this article at: http://dx.doi.org/10.21037/qims-20-1053

We have read with great interest the correspondence of Naeem et al. [2017] which demonstrated a very rich and informative review of imaging in mandibular fractures (1). It was mentioned in this review that the panoramic $\mathrm{X}$-ray is one of the most informative and sensitive radiographs in detecting a mandibular fracture (1). On the contrary, a limitation of this type of radiography is that it may not provide sufficient details of condylar fractures (1). Hereby, we aim to report a very unusual case of two fractures of the mandible: the first was a widely displaced parasymphyseal fracture that was not detected by the panorama at all; the other was a condylar fracture which was clearly visible in the same radiographic image.

A 24-year-old male was brought to the emergency department of a university hospital (Damascus, Syria) after falling from a height of one storey. As patient reported, he lost his balance while looking down from the balcony of his house, fell down, and landed on the edge of the sidewalk in a way that his lower lip and chin received the largest trauma. The medical history of the patient revealed no underlying systemic morbidity other than being a smoker. On arrival, the patient was conscious, orientated in time and space, and responsive with no convulsions nor vomiting. The patient reported that he did not lose consciousness, but had tinnitus, headache, and nosebleed when he fell. On head examination, swellings were observed in the area in front of the right ear and on the right side of the lower lip.
This caused facial asymmetry. Additionally, 2-cm irregular skin wound found in the mental region was cleansed and sutured. The patient had deviated, very painful and limited mandibular movement and mouth opening. This made the oral examination somewhat difficult. However, intraoral clinical assessment showed altered teeth positions (\#43, \#44, and \#45) and occlusion. These teeth showed signs of mild gingival bleeding, grade II to III mobility, and displacement. No large mucosal lacerations were observed except for the teared gingival margins around the mentioned teeth. After a full clinical evaluation, neurologists ordered a computed tomography (CT) scan of the patient's head to ensure the integrity of the central nervous system, while a panoramic $\mathrm{X}$-ray was requested by the maxillofacial surgeons to assess the jaws' condition.

It was very surprising when we compared the two images, i.e., panorama and CT. The panoramic radiograph showed normal findings except for a fracture of the right condylar neck. Although it was a high-quality digital panoramic image, the body of the mandible appeared intact with no visible fracture line nor step along its inferior border (Figure 1A). Radiographic reassessment of the jaws was done through the patient's CT scan. Unusual additional double-splitting fracture of the mandible in the region of the right parasymphysis was clearly detected then. The previous X-ray did not show this fracture at all, in spite of the fact that it was displaced and involving both lingual and labial cortical plates (Figure 1B).

^ ORCID: 0000-0001-9069-5069. 


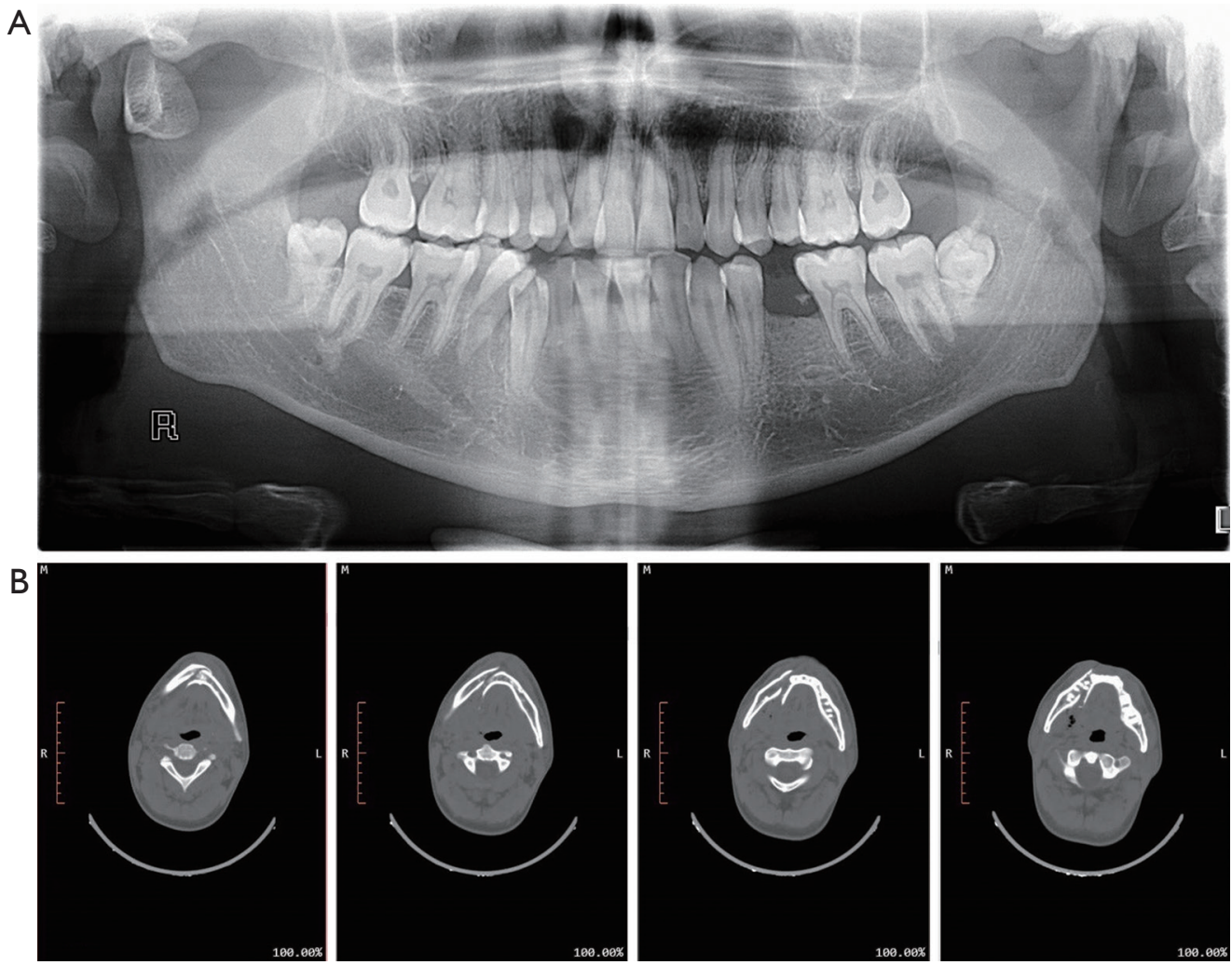

Figure 1 Radiographs of the patient. (A) The panoramic X-ray showing fractured right condylar process with no clear fracture in the rest of the mandible; (B) unusual double-splitting mandibular fracture appeared clearly on the CT image. CT, computed tomography.

On reviewing the medical literature, we have found that only two similar cases were reported heretofore $(2,3)$. Sever et al. [2011] reported a 26-year-old female patient presented with split mandibular fracture that resulted from an episode of epileptic seizure (2). Ersan and Ilgüy [2015] presented a 33-year-old male with incomplete lingual-cortex splitting fracture in the left mandibular corpus after falling from a height (3). Both reported fracture cases could not be detected on the panoramic $\mathrm{X}$-ray, and the fractures involved only the lingual cortical plates rather than the buccal/labial ones $(2,3)$.

The panoramic image is considered as one of the best in detecting mandibular fractures with a sensitivity of $92 \%$ (1). Lack of fracture displacement is usually the primary cause of missing fractures as a panoramic $\mathrm{X}$-ray is evaluated. This was not the case here. To the best of our knowledge, this is the first reported displaced mandibular fracture, involving both lingual and labial cortices, which could not be detected on the panoramic image. This might be explained by the fracture pattern that separately split each cortical plate, displacing them oppositely towards the lingual and labial plates rather than in vertical direction as shown in (Figure 1B). This pattern made the panoramic X-ray beam unable to capture the lines of this double fracture.

To conclude, displaced mandible fractures can be missed when only panoramic radiography is considered as a diagnostic tool. It is of utmost importance to perform a thorough clinical examination for every patient with maxillofacial trauma. This patient may have mandible fracture that is not detectable by conventional oral radiography. An additional CT or cone-beam CT scan may be required to confirm the diagnosis.

\section{Acknowledgments}

The authors would like to thank Dr. Ahmad Al-Nabulsi, all the clinicians, radiologists, nurses and assistants who took part in examining, diagnosing, and managing the presented case. Funding: None.

\section{Footnote}

Conflicts of Interest: All authors have completed the ICMJE 
uniform disclosure form (available at http://dx.doi. org/10.21037/qims-20-1053). The authors have no conflicts of interest to declare.

Ethical Statement: The authors are accountable for all aspects of the work in ensuring that questions related to the accuracy or integrity of any part of the work are appropriately investigated and resolved. The study was conducted in accordance with the Declaration of Helsinki (as revised in 2013). The patient agreed to use his clinical and radiographic findings for academic purposes while concealing all identifying personal data.

Open Access Statement: This is an Open Access article distributed in accordance with the Creative Commons Attribution-NonCommercial-NoDerivs 4.0 International
License (CC BY-NC-ND 4.0), which permits the noncommercial replication and distribution of the article with the strict proviso that no changes or edits are made and the original work is properly cited (including links to both the formal publication through the relevant DOI and the license). See: https://creativecommons.org/licenses/by-nc-nd/4.0/.

\section{References}

1. Naeem A, Gemal H, Reed D. Imaging in traumatic mandibular fractures. Quant Imaging Med Surg 2017;7:469-79.

2. Sever C, Kulahci Y, Uygur F, Karagoz H. Unusual split fracture of the mandible. J Craniofac Surg 2011;22:e10-1.

3. Ersan N, Ilgüy M. Diagnosis of unusual mandibular split fracture with cone-beam computed tomography. J Oral Maxillofac Radiol 2015;3:67-9.
Cite this article as: Albassal A, Al-Khanati NM, Harfouch M. Could a digital panoramic X-ray not detect a displaced fracture of the mandible? Quant Imaging Med Surg 2021;11(8):3890-3892. doi: $10.21037 /$ qims-20-1053 